\title{
LA POLICÍA DE HABITABILIDAD EN EL ÁMBITO DE LA COMUNIDAD AUTÓNOMA VALENCIANA
}

ANGEL LUIS SÁNCHEZ MARÍN Profesor Asociado de Derecho Administrativo.

\section{Sumario:}

I. Administración y Vivienda:

1. Base Constitucional

2. Intervencionismo administrativo en la materia.

II. La policía de habitabilidad y la de construcción: especial consideración a la Comunidad Autónoma Valenciana.

III. Las Cédulas de Habitabilidad en el ámbito de la Comunidad Autónoma Valenciana: concepto, naturaleza y régimen jurídico:

1. Concepto y naturaleza.

2. Régimen jurídico:

a) Aspectos objetivos y subjetivos de las Cédulas de Habitabilidad.

b) Competencia y Procedimiento

c) Registro Especial y Tasa de Habitabilidad

\section{ADMINISTRACIÓN Y VIVIENDA}

\section{Base Constitucional}

El artículo 47 de la Constitución Española determina que «todos los españoles tienen derecho a una vivienda digna y adecuada», obligando a los poderes púbicos a promover las condiciones neceserias y a establecer las normas pertinentes para hacer efectivo este derecho, regulando la utilización del suelo de acuerdo con el interés general para impedir la especulación. La Comunidad participará en las plusvalías que genere la acción urbanística de los entes públicos. 
De este precepto deducimos lo siguiente:

A) Se reconoce el derecho a la vivienda, aunque no se trata de un derecho público subjetivo, de modo individualizado, ya que si bien se trata de un derecho vital, que responde a una necesidad humana ineludible, como es la de tener un lugar donde habitar, sin embargo, en sentido jurídico, por encontrarse este precepto dentro de los Principios rectores de la Política Social y Económica del Estado (Capítulo III del Título I de la CE), debe hacerse en los términos que plantea el art. 53, 3 de la CE. Lo que remite a la legislación de desarrollo del precepto y a una actuación pública tendentes a satisfacer este derecho.

B) Que la vivienda a que se refiere este derecho básico sea calificada por la CE de «digna y adecuada», significa no sólo que ha de reunir, en sí misma considerada, condiciones de habitabilidad, sino también su inserción en el medio urbano y, en su caso, rural, esto es, que la vivienda se halle en relación con su entorno, que en el medio urbano requiera obras y servicios de urbanización y en el medio rural la conservación de sus valores propios y característicos.

C) El precepto mencionado termina exigiendo una intervención pública en esta materia ordenada a hacer efectivo este derecho y a impedir la especulación del suelo, no sólo medianmte la regulación del uso y aprovechamiento urbanístico, sino también mediante el cumplimiento de la exigencia de que la comunidad participe en los incrementos de valor - plusvalías- derivadas de la actividad urbanística.

\section{La acción administrativa de la vivienda}

La acción administrativa en materia de vivienda es tan vieja como la propia Administración, pero por regla general, y hasta el siglo XX, aquella acción se limitaba a cuestiones de carácter policial: se trataba de garantizar la seguridad y solidez de las construcciones, las condiciones higiénico-sanitarias de las viviendas, el derribo de edificios ruinosos, etc... y en materia de urbanismo a garantizar la altura máxima y mínima de las edificaciones y su lineación. Con todo, no existía un problema de la vivienda, pues ordinariamente se construían las suficientes para albergar a toda la población o al menos el déficit de viviendas no alcanzaba graves proporciones.

De cualquier forma es lo cierto que desde principios de siglo las construcciones de vivienda no crecieron al ritmo adecuado y preciso. Las causas de ello han sido muy variadas: un crecimiento rápido de la población con una fuerte emigración a las ciudades; fuga del capital privado hacia otras inversiones más rentables que las viviendas; escasez de materiales de contrucción; destrucciones suscitadas por conflictos bélicos, etc...

Ante el problema de la vivienda que a principios de siglo surgía, el Estado optó 
por contemplar el problema desde una perspectiva económica más general: así puede disponer la congelación de alquileres para reducir los efectos de la inflación sobre las clases de rentas más bajas o programar la construcción de viviendas para combatir el paro. Pero la verdadera política de vivienda es aquella por la que se fomenta la construcción de viviendas a través de medidas fiscales (exención o reducción de impuestos), crediticias (anticipos sin interpés y préstamos a largo plazo y con interés bajo), primas o subvenciones a la construcción, suministro de materiales escasos, etc... Hay que añadir a esto la acción de polícía de la Administración en esta materia (policía especial de la vivienda) y la acción administrativa de servicio público, cuando es el Estado el que se transforma en constructor de viviendas.

Las manifestaciones más importantes de la actividad de policía en materia de vivienda que han ido apareciendo a través de las vigentes legislaciones son las siguientes, a saber:

a) Un control de cumplimiento de la normativa jurídica con el fin de que todo el desarrollo de las edificaciones de viviendas de Protección Oficial se ajusten a las leyes y reglamentos vigentes de aplicación.

b) Establecimiento de un sistema sancionador que va desde la imposición de multas hasta la descalificación de la vivienda, dependiendo de la gravedad de la infracción. En el caso de la descalificación, llevaba aparejada la pérdida de beneficios.

c) Regulación del uso y disfrute de las viviendas, no pudiendo ser destinadas a otro fin que el establecido, ya se trate de venta o arrendamiento.

d) Se contempla también una Policía de Habitabilidad y otra de Construcción a las que después nos referiremos.

Como objetivo crítico de las manifestaciones de la actividad administrativa de policía en esta materia hay que destacar — seguimos en esto a Bando Casado— la falta de rigor en el cumplimiento de la normativa, ya que no se ha exigido una observancia por parte de los particulares. Esto ha traído consigo que las viviendas no alcancen el fin para el que fueron construidas, surgiendo paralelamente el objetivo especulativo. Tan sólo cuando se producía denuncia por un tercero, el mecanismo sancionador se ponía en marcha. Tampoco se ha llevado con la debida supervisión, la aplicación de la normativa sobre el uso y disfrute de las viviendas, pues se han presentado casos frecuentes en que una persona era titular de más de una vivienda destinada a domicilio permanente del titular, lo cual ha venido generando que las viviendas de protección oficial no cumplan con el objetivo social para el que fueron concebidas.

De otro lado, no ha existido una Policía de mantenimiento que tuviese la misión de vigilar y cuidar las viviendas, para que se mantengan en perfecto estado de conservación. 
La actividad administrativa de policía en materia de vivienda —nos dice el autor antes citado - necesita una adecuación a la realidad sociológica actual, que atañe a la construcción de viviendas, su uso y disfrute para que cubran la demanda social a la que van destinadas.

\section{LA POLICÍA DE HABITABILIDAD: ESPECIAL REFERENCIA A LA COMUNIDAD ATÓNOMA VALENCIANA}

Dentro de la actividad administrativa de policía encontramos la policía de habitabilidad y la de construcción.

Con la primera se trata de garantizar que el acceso a una vivienda se realiza reuniendo ésta las condicionesde salubridad e higiene que marca el ordenamiento jurídico (Reglamento de Sanidad Municipal de 9-2-1925, Orden de 29-2-1944 que establece las condiciones higiénicas mínimas que han de reunir las viviendas, Ley General de Sanidad de 25-4-1986, etc...).

Esto era comprobado por las Delegaciones Provinciales del MOPU, quienes estaban facultadas para expedir tras las comprobaciones petinentes y previo pago de la tasa correspondiente, el documento acreditativo de tales extremos, que no era otro que la Cédula de Habitabilidad (regulada básicamente por la siguiente normativa: Orden de 23 de noviembre de 1940 por la que se organiza la Fiscalía de la Vivienda y el Decreto $469 / 1972$ de 24 de febrero por el que se establece el procedimiento de expedición de las cédulas de habitabilidad).

En la actualidad tales cuestiones son realizadas por las Comunidades Autónomas, ya que, éstas en virtud del art. 148, 1, 3 de la CE han asumido a través de sus respectivos Estatutos de Autonomía (así, la C.A. Valenciana art. 31,9) competencia exclusiva (potestad legislativa, ejecutiva y reglamentaria) en materia de viviendaconsecuentemente, en relación con la policía de vivienda.

La Comunidad Autónoma Valenciana ha venido a considerar, con la finalidad de acercar la Administración al ciudadano, que deben ser los municipios comprendidos en su ámbito territorial los que comprueben las condiciones de habitabilidad de las viviendas y expidan las correspondientes cédulas, lo que ha llevado a que la Ley de Tasas de esta Comunidad Autónoma delegue, en su Disposición Adicional Quinta, esta competencia en aquéllos.

Obviamente, al requerir la técnica de la delegación aceptación de los municipios -ésta no se puede imponer obligatoriamente a los mismos, pues, entendemos se vulneraría el principio constitucional de la autonomía local - en defecto de que éstos asuman tal competencia será la propia Comunidad Autónoma quien la asuma y la lleve a cabo. Esta lo hará a través de los Servicios Territoriales de Arquitectura y Vivienda de la Consejería de Obras Públicas que existen en cada una de las tres provincias que conforman esta Comunidad Autónoma. Eso sí, los municipios que 
acepten la delegación vendrán obligados a hacer una relación mensual de todas las cédulas expedidas y vendrán obligados a enviarlas a los referidos Servicios Territoriales.

Frente a esta postura, nos encontramos con la mantenida por la Generalidad Catalana, la cual mantiene para sí la facultad de otorgar y revocar las cédulas de habitabilidad atribuyendo a los Ayuntamientos la obligación de velar por el cumplimiento de las condiciones de habitabilidad de la vivienda (artículo 6 Decreto 129/1984 de 18 de abril).

No nos encontramos aquí, como ha señalado el Tribunal Supremo (Sentencias de 21-7-1987; 6-11-1986), con una transferencia de competencia en favor de los Ayuntamientos, pues, la LBRL establece que los municipios pueden realizar actividades complementarias — sin necesidad, por tanto de transferencia- en determinadas materias, entre ellas la vivienda. Entre las complementarias en este campo figuran precisamente las contempladas por el art. 6 del precitado Decreto.

Pero volviendo a la Comunidad Autónoma Valenciana, hemos de señalar que ante la diseminación de normas existentes en materia de cédulas de habitabilidad y, con la finalidad última, de proteger los derechos de los administrados, el Consejo de Gobierno Valenciano dicta el Decreto 161/1989 de 30 de octubre (DOGV 8-111989) por el que se regula el procedimiento de expedición de las cédulas de habitabilidad, quedando así inaplicada en el ámbito de esta Comunidad la normativa estatal que antes mencionamos. A este Decreto nos referiremos después más detalladamente.

Por otro lado, ante el desfase que sufre con la realidad presente de la construcción la normativa estatal vigente en materia de habitailidad y diseño (Orden de 292-1944; Orden M. 20-Mayo-1969 que aprobó las Ordenanzas Provinciales de Viviendas de Protección Oficial), el Consejo de Gobierno Valenciano dictó el Decreto 85/1989 de 12 de junio (DOGV 23-6-1989) sobre normas de habitabilidad y diseño, el cual ha sido desarrollado por la Orden de 22-4-91 (DOGV 22-5-1991).

En este Decreto se establece que todas las viviendas existentes en el ámbito de la Comunidad Autónoma Valenciana deberán ajustarse, para la concesión de la cédula de habitabilidad, a las condiciones que se determinan en la Orden de desarrollo ya mencionada.

Todas las viviendas de nueva planta, independientemente de su régimen de protección, deberán cumplir las exigencias y condiciones que se determinan en la precitada Orden. Tales condiciones no son, hoy en día, sólo de salubridad sino también espaciales, de seguridad y dotación.

Pues bien, frente a la policía de habitabilidad existe una policía de la construcción que tiene como fin garantizar la seguridad y el ornato de las construcciones. Esta policía se residencia en los municipios y se manifiesta de la siguiente forma: la construcción de viviendas se ha de ajustar a las Ordenanzas Municipales de construcción y, en general, a las normas del planeamiento urbanístico; necesidad de 
obtener la previa licencia de construcción; demolición de edificios declarados ruinosos por el Ayuntamiento, etc...

\section{LAS CÉDULAS DE HABITABILIDAD EN EL ÁMBITO DE LA COMUNIDAD AUTÓNOMA VALENCIANA: CONCEPTO, NATURALEZA Y RÉGIMEN JURÍDICO}

\section{Concepto y naturaleza}

a) Concepto:

Como dice Chacón Ortega, la Cédula de Habitabilidad es el documento expedido por la Admimistración Pública en el ejercicio de funciones de policía, con la doble finalidad de controlar las condiciones de salubridad e higiene de los edificios destinados a viviendas y alojamientos de carácter residencial y de servir de medio eficaz para dar cumplimiento a la estadística de edificación y viviendas.

No debe confundirse - nos dice Pons González y Arco Torres- la Cédula de Habitabilidad con la licencia de primera utilización; y a su vez ésta con la licencia de construcción.

Por medio de la Cédula de Habitabilidad sólo se controla las condiciones de salubridad e higiene de las viviendas; mientras que, la licencia de primera utilización, tiene por objeto confrontar la obra realizada con el proyecto presentado que ampara la licencia municipal concedida, y si se han cumplido o no las condiciones en ella establecidas.

En la Sentencia de 30 de julio de 1983 de la Audiencia Territorial de Valladolid se viene a decir que no existe vinculación o congruencia entre ambas licencias, con un régimen diferente en orden a su concesión, «sin que la relación de medio a fin existente entre ambas, implique un grado de dependencia tan relevante, que concedida la primera debe forzosamente otorgarse la segunda».

\section{b) Naturaleza:}

La Cédula no es sino un acto administrativo de policía preventiva; más concretamente, una autorización o permiso administrativo. En la doctrina es clásica la concepción de Ranelletti (1893), para quien, mediante la autorización administrativa, la Administración remueve el obstáculo o limitación que se opone al libre ejercicio de un derecho subjetivo preexistente (en nuestro caso el derecho a ocupar una vivienda), mediante la comprobación administrativa de que dicho ejercicio no pone en peligro ni perjudica el interés público protegido por el ordenamiento mediante la exigencia de determinadas condiciones o requisitos. 
Con base en esta idea del derecho preexistente cuya actuación o ejercicio requiere de la remoción de límites mediante la autorización (no se puede ocupar una vivienda que no reúna las condiciones de salubridad e higiene que marca el ordenamiento jurídico), la doctrina clásica considera que ésta tiene carácter declarativo.

En su aspecto formal decir que nos encontramos ante un procedimiento reglado: a la hora de decidir sobre su otorgamiento, la Administración carece de toda libertad de elección, debiendo ceñirse, estrictamente, a la comprobación de si el solicitante cumple o no los requisitos establecidos en el Decreto 161/89, al que la Administración valenciana en todo momento debe ajustarse, y ello, como establece reiterada jurisprudencia del Tribunal Supremo, en el doble sentido de «tener que denegar las autorizaciones administrativas que se opongan a las normas legales pertinentes, y tener que conceder las que a las mismas se acomoden».

Una vez obtenida la cédula de habitabilidad el sujeto autorizado podrá ocupar la vivienda, entendiéndose otorgada aquélla a «salvo el derecho de propiedad y sin perjuicio de terceros» (según la expresiva fórmula utilizada en el régimen local por el RSCL, art. 12).

\section{Régimen jurídico}

\section{A) Aspectos objetivos y subjetivos del deber de obtener la Cédula de Habitabilidad:}

La cédula, de conformidad con el art. 2 del Decreto 161/1989 que comentamos, debe ser solicitada:

a) Con carácter previo al momento de ocupar una vivienda o alojamiento residencial, tanto si se accede a ésta como propietario o como arrendatario, salvo en el caso de la primera ocupación de las viviendas de protección oficial (art. 103 del Decreto 2114/1968 de 24 de julio por el que se aprueba el Reglamento de V.P.O.); o rehabilitadas al amparo de la normativa vigente para esta clase de actuaciones protegibles.

b) Como la cédula de habitabilidad tiene un período de validez de cinco años, debemos entender que transcurrido este tiempo habrá que solicitar una nueva cédula, aún cuando no haya cambiado de ocupación, pues la anterior habrá caducado. Por contra, en la Generalidad catalana la cédula caduca a los diez años de su expedición.

Están legitimados para solicitarla los promotores (personas físicas o jurídicas) de viviendas nuevas después de acabadas las obras de nueva construcción; los propietarios de las viviendas y, en su defecto, el usuario de las mismas (arrendatario, usufructuario, comodatario, etc...). 


\section{B) Competencia y procedimiento}

\section{a) Competencia:}

Según la única Disposición Adicional de este Decreto «la competencia para otorgar la cédula corresponderá a los Servicios Territoriales de la Dirección General de Arquitectura y Vivienda de la Consellería de Obras Públicas, Urbanismo y Transporte».

¿Qué órgano administrativo de estos Servicios Territoriales ha de ejercer esa competencia? Según el art. 55, 1 del Reglamento Orgánico y Funcional de esta Consellería (Decreto 65/1991 de 15 de abril), correspónderá a los Jefes de los Servicios Territoriales.

En los Ayuntamientos que hayan asumido esta competencia por delegación será el Alcalde-Presidente de la Corporación quien expedirá la cédula, pudiendo la Corporación local dar a la cédula el carácter simultáneo de licencia de ocupación, refundiendo ambos documentos en uno solo que acreditará de un lado el cumplimiento de la normativa sobre habitabilidad de las viviendas y de otro el de la normativa urbanística.

\section{b) Procedimiento:}

El procedimiento a seguir es el regulado en los artículos 3, 4 y 5 del precitado Decreto aplicándose, con carácter supletorio, la Ley 30/92, de 26 de noviembre, de Régimen Jurídico de las Administraciones Públicas y del Procedimiento Administrativo Común.

b.1. Iniciación del Procedimiento.

Se trata de una iniciación a instancia de parte. A voluntad del peticionario de la Cédula, el procedimiento se pone en marcha.

Como ya sabemos es un procedimiento inexcusable cuando se pretende llevar a cabo la ocupación de una vivienda.

Y si el interesado en ocupar una vivienda omite el procedimiento, ocupa la vivienda sin obtener el permiso de ocupación, comete un ilícito administrativo que sorprendentemente no sanciona este Decreto; es más, al no aplicarse en la Comunidad Valenciana, la normativa estatal aplicable a este caso (o sea, el Decreto de 23 de noviembre de 1940 y disposiciones concordantes) no se podrá sancionar al infractor en ningún caso. Frente a esta postura, la Generalidad Catalana sí recogió en el Decreto 129/1984 ya mencionado, la aplicación del Decreto estatal mencionado, el cual, prevé multas para estos supuestos, cosa que nos parece del todo lógica y necesaria.

La petición se presenta acompañada de los documentos que señala este Decreto - diversos según se trate de dificios de nueva planta o de segunda o posterior ocupación- en el Registro General de Entrada del Servicio Territorial competente.

Entre los domuentos a acompañar cuando se trate de viviendas de nueva planta destacamos dos, a saber: 
b.1.1. Certificado final de obra expedido por el Arquitecto Superior y Técnico, Directores de la Obra, y visado por los respectivos colegios profesionales.

Con éste se pretende asegurar que en la realización total de la obra han intervenido Técnicos competentes que asuman la responsabilidad que les corresponde en el resultado final de acuerdo con las disposiciones vigentes.

Cuando en la obra han intervenido Técnicos Directores y éstos no llegan a expedir el certificado final de obra sin causa justificada, el Decreto establece un procedimiento supletorio para la obtención de la cédula. Así, la no presentación del certificado técnico de terminación de obras puede producirse como consecuencia de discrepancias económicas o de diversa índole entre Ténicos y promotores, que no debe perjudicar a terceros adquirentes y usuarios que precisen la cédula. En este caso, la Administración actuante requerirá a los Directores Técnicos de la Obra que aporten en el plazo de quince días tal certificado y sólo cuando éstos no contestasen o no alegaren justificadas razones de carácter técnico o defectos de habitabilidad, procederá la Administración tras la inspección de sus Servicios Técnicos competentes, a expedir la correspondiente cédula.

\section{b.1.2. Licencia Municipal de Edificación.}

Esta es preciso exigirla para evitar el caso actualmente posible de que se considere oficialmente habitable una vivienda construida sin licencia municipal de obras y por tanto clandestina.

No obstante lo anterior, la Sala Tercera del Tribunal Supremo en su sentencia de 22-Mayo-1989 consideró que «...la única exigencia para conceder la cédula de habitabilidad no es otra que la de que lo edificado - adecuada o inadecuadamente, desde el punto de vista urbanístico- cumpla estrictamente las condiciones de salubridad e higiene sanitarias legalmente requeridas para que una vivienda pueda habitarse, de suerte que la denegación de la cédula no puede justificarse más que por el comprobado no cumplimiento de aquéllas...».

Por otro lado, entre los documentos a acompañar cuando se trate de segunda o posterior ocupación destacamos la necesidad de certificación expedida por técnico competente visada por el respectivo colegio profesional o, en su caso, por Técnico de la Administración Municipal competente que acredite que la vivienda cumple la normativa técnica de habitabilidad de la Generalidad Valenciana aplicable, y que no se trata de una edificación de nueva planta, con especificación de la clase de suelo en que la vivienda se ubica.

\section{b.2. Instrucción del Procedimiento.}

A la vista de la documentación presentada el órgano administrativo territorial competente podrá realizar y/o recabar las comprobaciones, inspecciones a las viviendas e informes que estime pertinentes.

Cuando de la documentación presentada y/o de los informes técnicos e inspecciones practicadas se deduzca el incumplimiento de la normativa técnica de habitabilidad establecida por la Generalidad Valenciana, el órgano administrativo 
territorial competente requerirá al interesado y, en su caso también a la Dirección facultativa, para que proceda a subsanar las deficiencias de habitabilidad observadas en el plazo que estime oportuno.

\section{b.3. Terminación del Procedimiento.}

La terminación del procedimiento puede ser normal (por resolución expresa, otorgando o denegando la cédula) o anormal, por desistimiento, caducidad, renuncia, o por silencio administrativo.

La resolución denegatoria tiene que ser motivada. Entre las causas que pueden justificar la denegación de la cédula están comprendidas la no realización de las obras de subsanación a la que antes nos referíamos o la suspensión de los actos de edificación y de uso del suelo y otras medidas de protección de la legalidad urbanística que se adopten por el Alcalde o por el Conseller de Obras Públicas, Urbanismo y Transporte de la Generalidad valenciana en uso de sus respectivas competencias.

Contra la resolución denegatoria, que no pone fin a la vía administrativa, cabe interponer Recurso Ordinario ante el Director General de Arquitectura y Vivienda en el plazo de un mes, contados a partir del siguiente al de la notificación de la resolución, conforme dispone el art. 111 de la Ley de Procedimiento Administrativo, la Ley 7/1985 y Real Decreto Legislativo 781/1986. La interposición del recurso fuera de plazo conlleva la inadmisibilidad del mismo conforme reiterada jurisprudencia del Tribunal Supremo (Sentencias 11-3-67: 15-2-72, entre otras).

No establece el Decreto comentado qué ocurriría si la Administración actuante no dictase regulación expresa, es decir, si utilizara el tan criticado silencio administrativo. Esto llevó a que las Compañías suministradores de Gas, Electricidad, Agua y Teléfono junto al Ayuntamiento de Sagunto interpusieran sendos recursos de reposición contra aquél, al considerar que tal cosa podría vulnerar los derechos de los administrados. El Consell de Gobierno de la Generalidad Valenciana estimó estos recursos por Acuerdo de 12-2-1990 y modificó el Decreto estableciendo un silencio positivo de un mes, transcurrido el cual la cédula se entenderá otorgada, salvo claro está se adquirieran con ella facultades en contra del ordenamiento jurídico, al igual que ocurría en la regulación catalana.

Según la jurisprudencia, los plazos de silencio administrativo han de computarse en la forma más desfavorable para la Administración infractora del deber de dictar resolución expresa. Así, el cómputo se inicia desde el momento mismo de la presentación de la solicitud o del proyecto o propuesta, plazo que es menester completar antes de que se produzca no ya la resolución tardía, sino su notificación. Por otra parte, la interrupción producida por requerimiento de aportación de documentos al solicitante no implica que sea necesesario comenzar un nuevo cómputo del total del plazo a partir de la subsanación. Por el contario, la jurisprudencia entiende que no se trata de un plazo de prescripción, sino de caducidad, y que, en consecuencia, subsanados los defectos, sólo es necesario completar el tiempo que resta del plazo (Sentencias 16-5-73; 16-3-74). 
b.4. Efectos y condicionamientos de las cédulas de habitabilidad.

Otorgada la cédula se puede pasar a ocupar la vivienda estando en disposición de formalizar con las empresas suministradoras de los servicios de agua, electricidad, gas y teléfono los respectivos contratos de suministro.

En general, las autorizaciones administrativas no son objeto de revocación por parte de la Administración; sin embargo, la cédula puede ser objeto de esta medida en los siguientes supuestos, a saber:

habitabilidad.

b.4.1. Cuando la vivienda deje de tener el nivel exigible de

b.4.2. Cuando la documentación aportada contenga circunstancias no adecuadas a la realidad o veracidad que hayan inducido a la Administración a resolver erróneamente.

Además, la Administración se reserva la facultad de inspeccionar en cualquier momento las viviendas para comprobar el nivel de habitabilidad exigible. Se quiere así instaurar una policía de mantenimiento.

\section{C) Registro especial y Tasa de Habitabilidad}

\section{a) Registro especial:}

La Administración actuante llevará un Registro especial en el que se inscribirán las solicitudes, concesiones y denegaciones de cédulas conteniendo los requisitos que establece la Orden de 10 de noviembre de 1989 del Conseller de Obras Públicas, especificando si es de primera, o de segunda o posterior ocupación.

Esta Orden establece que los municipios actuantes también lleven un libro registro especial en el que se tomará razón de todos los edificios de viviendas libres promovidos en el territorio municipal.

\section{b) Tasa de Habitabilidad:}

El artículo 8 del Decreto comentado establece que «la expedición de la cédula generará la obligación del pago de tasas devengadas según la normativa aplicable en la materia».

Esta no es otra que la Ley de Tasas de la Generalidad Valenciana de 22-12-1984. La misma establece que están obligados al pago de la tasa los dueños y cedentes en general de los cuartos, locales y viviendas, que lo ocupen por sí, o los entreguen a distintas personas para que los habiten a título de inquilinos o en concepto análogo.

La cuota a pagar se halla multiplicando la base imponible (que será el resultado de multiplicar el módulo «M» vigente en el momento de la expedición para las viviendas de protección oficial por la superficie útil de la vivienda) por el tipo de gravamen vigente en cada momento (hoy fijado en $0,021 \%$ ).

Finalmente, dejar reseñado que están exentos del pago de la tasa: 
b.1. Las personas con rentas o ingresos familiares anuales que no superen 2,5 veces el salario mínimo interprofesional computado anualmente.

b.2. Las residencias, internados, colegios y centros similares de carácter benéfico o asistencial carentes de ánimo de lucro. 